\title{
Medical equipment donation in low- resource settings: a review of the literature and guidelines for surgery and anaesthesia in low-income and middle-income countries
}

\author{
Isobel H Marks (D) , ${ }^{1}$ Hannah Thomas, ${ }^{2}$ Marize Bakhet, ${ }^{3}$ Edward Fitzgerald ${ }^{4}$
}

\begin{abstract}
To cite: Marks IH, Thomas $\mathrm{H}$, Bakhet M, et al. Medical equipment donation in lowresource settings: a review of the literature and guidelines for surgery and anaesthesia in low-income and middle-income countries. BMJ Global Health 2019;4:e001785. doi:10.1136/ bmjgh-2019-001785
\end{abstract}

Handling editor Stephanie M Topp

- Additional material is published online only. To view, please visit the journal online (http://dx.doi.org/10.1136/ bmjgh-2019-001785).

Received 20 June 2019 Revised 7 August 2019 Accepted 31 August 2019

Check for updates

(C) Author(s) (or their employer(s)) 2019. Re-use permitted under CC BY-NC. No commercial re-use. See rights and permissions. Published by BMJ.

${ }^{1}$ Primary Care and Public Health, Imperial College, London, UK

${ }^{2}$ Edinburgh Medical School,

The University of Edinburgh, Edinburgh, UK

${ }^{3}$ Primary Care and Public Health, Imperial College London School of Public Health, London, UK ${ }^{4}$ Lifebox Foundation, Lifebox, London, UK

Correspondence to Dr Isobel H Marks; isobel.h.marks@gmail.com

\section{ABSTRACT}

Background Medical equipment donation to low-resource settings is a frequently used strategy to address existing disparities, but there is a paucity of reported experience and evaluation. Challenges such as infrastructure gaps, lack of technological and maintenance capabilities, and non-prioritisation of essential supplies have previously been highlighted. This pragmatic review summarises existing guidelines and literature relevant to surgical and anaesthesia equipment, with recommendations for future initiatives and research.

Methods Retrospective literature review including both academic and grey literature from 1980 to 2018 . We conducted a narrative synthesis to identify key factors that were condensed thematically.

Results Thirty-three biomedical equipment donation guidelines were identified from governments, WHO, World Bank, academic colleges and non-governmental organisations, and 36 relevant studies in peer-reviewed literature. These highlighted the need to consider all stages of the donation process, including planning, sourcing, transporting, training, maintaining and evaluating equipment donation. Donors were advised to consult national guidelines to ensure equipment was appropriate, desirable and non-costly to both parties. User training and access to biomechanical engineers were suggested as necessary for long-term sustainability. Finally, equitable partnerships between donors and recipients were integral to reducing inappropriate donations and to improve followup and evaluation.

Conclusion There is a paucity of evidence on the causes of success or failure in medical equipment donation, despite its domination of equipment sourcing across many low-resource settings. Equitable partnerships, consultation of policies and guidelines, and careful planning may improve equipment usability and life span. A concerted effort is required to increase awareness of guidelines among health professionals worldwide.

\section{INTRODUCTION}

The need for improvement of surgical systems, especially in low-resource settings,

\section{Key questions}

What is already known?

- There is a paucity of evidence on the varying rates of success of medical equipment donation to low-resource settings.

What are the new findings?

- Reviewed literature recommended approaching donation as a collaborative process, with an equitable partnership between donors and recipients.

- Planning, sourcing, transport, installation, training, maintenance and evaluation are key components.

- Funding for maintenance teams is a particularly neglected area and ought to be considered during donation planning.

What do the new findings imply?

- Five key areas should be considered when assessing the feasibility of biomedical equipment donation: Human resources: on-site capacity, such as trained physicians, nurses and biomedical technicians to operate and maintain the equipment.

Environment: space, electricity, water, oxygen supply and ventilation. Standardisation with local equipment, low energy consumption, ease of maintenance and avoidance of environmentally hazardous substances.

Material resources: ancillary equipment supplied either locally or from overseas, as well as replacement parts and associated supply chains.

Maintenance resources: workforce training, considering both material and financial capacities.

Educational resources: capacity to train the workforce in the clinical implementation of the equipment, as well as in the correct interpretation of results.

has gained traction in recent years. An estimated 4.8 billion people lack access to safe, timely and affordable surgical and anaesthesia care worldwide, with 143 million additional surgical procedures required each year. $^{12}$ Where surgical care is available in 
low-resource settings, perioperative mortality can be up to three times higher than in high-resource settings. ${ }^{3}$

While the causes are multifactorial, a shortage or absence of essential biomedical equipment is frequently described. ${ }^{4}$ This includes anaesthetic machines, pulse oximeters, airway equipment, sterilisers and other basic consumables such as catheters, cannulas, face masks and sterile gloves. ${ }^{56}$

Lack of planning and collaboration can mean that equipment donated with 'good intentions' to help address these shortages is inappropriate, ineffective or dangerous. Such donations can actively inhibit healthcare delivery and further burden healthcare providers. ${ }^{7-10}$ 'Dumping' of obsolete equipment by high-income countries (HICs) has been described as 'morally reprehensible' and has received adverse media attention. ${ }^{11-13}$ An 'anything is better than nothing' attitude, coupled with a donor-recipient power imbalance, has been cited the central reason for poor-quality donations. ${ }^{912} 14$ Recipients may be too embarrassed to point out the futility of donor efforts or may find it culturally inappropriate to decline a gift. ${ }^{15}$ As a result, 'medical equipment graveyards' of obsolete or broken donated biomedical equipment are commonly seen in hospitals across low-income and middle-income countries (LMICs).

Understanding the complexity of health systems is also necessary for successful donation of medical equipment. Structural factors affect both the availability and functionality of medical equipment. These include infrastructure gaps, chronic underinvestment in equipment maintenance and repair, and inappropriate design of medical equipment for low-resource setting. ${ }^{16}$ This has resulted in $40 \%$ of healthcare equipment in LMICs being out of service, compared with less than $1 \%$ in HICs. ${ }^{16}$

Health technologies are overwhelmingly designed for HICs, with reliable infrastructure and trained biomedical engineers to regularly maintain equipment. In LMICs, however, continuous electricity is estimated to be accessible to $59.1 \%$ of hospitals providing essential surgical care. ${ }^{17}$ Perry and Malkin describe a lack of 'Health Technology Management', including the absence of regular checks, failure to report problems and a paucity of technical knowledge. ${ }^{18}$ Such shortages curtail services; in Niger, half of referrals at a district orthopaedic hospital were made due to a lack of necessary materials for treatment at the referring healthcare centre. ${ }^{19}$

With momentum growing to address the inequalities in surgical provision, it is necessary to critically examine medical equipment donations to LMICs. This is particularly important, given that the WHO estimates that $95 \%$ of medical equipment in LMICs is imported and $80 \%$ of it is funded by international donors or foreign governments. ${ }^{2021}$ Medical equipment donation can be an expensive undertaking with little proven impact on health outcomes. ${ }^{22}{ }^{23}$ While up to $70 \%$ of medical equipment in sub-Saharan Africa is donated, ${ }^{14} 24$ only $10 \%-30 \%$ of donated equipment becomes operational. ${ }^{2025} 26$
This pragmatic review aimed to evaluate the way medical equipment is sourced and donated, as well as the responsibilities of donors, users, manufacturers and managers involved. It considers each stage of the donation process and recommendations for successful donation.

\section{METHODS}

We defined medical equipment as medical devices used for the specific purposes of diagnosis, treatment and/or rehabilitation of disease that require calibration, maintenance, repair, user training and decommissioning. ${ }^{26}$ We searched PubMed for the terms 'equipment', 'donation', 'equipment and supplies', 'global surgery', 'anaesthesia' and 'LMIC'. We also searched wider literature surrounding medical equipment donation for surgical and anaesthesia care. Concurrently, we searched for grey literature using internet searches and via Ministry of Health websites to find pre-existing non-governmental organisations (NGOs) and governmental medical equipment donation guidelines.

We limited our search to literature published between 1980 and 2018, in accordance with the growth of literature in the field. Guidelines and articles were sourced from United Nations agencies, the World Bank, Ministry of Health and the NGO sector. Articles that did not describe the process of medical equipment donation for surgical and anaesthesia care were excluded. Only guidelines, research articles and websites in English were examined. We conducted a narrative synthesis of the guidelines and thematically grouped key points into general principles of successful donation. These were organised under the headings of planning, sourcing, transport, installation, training, and follow-up and evaluation. Patients were not involved in the conception of this project.

\section{RESULTS}

In total, 8 government donation policies, $12 \mathrm{WHO}$ and World Bank documents, 2 academic college guidelines, 11 NGO guidelines and 36 articles in peer-reviewed journals were examined (see table 1). Further findings are categorised and summarised below for each stage of the donation process. A summary of the necessary steps is demonstrated in figure 1.

\section{Donation planning}

The initial stage of medical equipment donation should involve establishing bilateral and equitable partnerships between donors and recipients. ${ }^{27}$ Leaders on both sides are required to be partnership coordinators, and local clinical leads, biomedical engineering departments, suppliers and health ministries should be consulted in the development of a formal, agreed donation plan. Inclusion of hospital procurement managers, who may be better informed on local equipment policy and needs, may help donations to succeed. ${ }^{28}$

Numerous published guidelines encourage donors to actively follow national donation policies, where they 
Table 1 All reviewed texts from government, academic colleges, WHO and World Bank publications and NGOs

\begin{tabular}{|c|c|c|}
\hline & Author & Year \\
\hline \multicolumn{3}{|l|}{ National government guidelines } \\
\hline $\begin{array}{l}\text { Policy and procedures guidelines for gifts and donations to the } \\
\text { Ministry of Health of Jamaica }\end{array}$ & Ministry of Health, Jamaica & 2014 \\
\hline Donation policy for medical equipment & Ministry of Health Fiji & 2012 \\
\hline Medical equipment donation directive & $\begin{array}{l}\text { Ethiopian Food, Medicine and Healthcare } \\
\text { Administration and Control Authority }\end{array}$ & 2012 \\
\hline $\begin{array}{l}\text { National comprehensive study on the associated risks, donation } \\
\text { and disposal of used medical devices in the Kingdom of Saudi } \\
\text { Arabia }\end{array}$ & $\begin{array}{l}\text { Kingdom of Saudi Arabia, Food and Drug } \\
\text { Authority, Medical Devices Sector }\end{array}$ & 2011 \\
\hline Guidelines for equipment donation scheme & Medical Council of India & 2010 \\
\hline $\begin{array}{l}\text { Guidelines for the donation of medicines, medical supplies and } \\
\text { equipment to Sierra Leone }\end{array}$ & $\begin{array}{l}\text { Government of Sierra Leone Ministry of } \\
\text { Health and Sanitation }\end{array}$ & 2004 \\
\hline Guidelines on medical equipment donation & $\begin{array}{l}\text { Transitional Islamic Government of } \\
\text { Afghanistan, Ministry of Health, Healthcare } \\
\text { and Promotion Department }\end{array}$ & 2003 \\
\hline $\begin{array}{l}\text { Guidelines for medical equipment, spare parts, and maintenance } \\
\text { services donation }\end{array}$ & Palestinian National Authority & - \\
\hline
\end{tabular}

Academic colleges

Guidelines for medical equipment donation

Medical Equipment Maintenance Project for the Pacific guidelines for the donation of medical to Pacific Island Countries
American College of Clinical Engineering 1995

Royal Australasian College of Surgeons and AusAID

\section{WHO and World Bank publications}

Local production and technology transfer to increase access to WHO

medical devices: addressing the barriers and challenges in low- and middle-income countries. Geneva, Switzerland: WHO, 2012:17.

\section{Local production and technology transfer to increase access to}

medical devices: addressing the barriers and challenges in low- and middle-income countries. Geneva, Switzerland: WHO, 2012:17.

Medical device donations: considerations for solicitation and

WHO

2011 provision. Geneva, Switzerland: WHO, 2011.

\begin{tabular}{lll} 
Compendium of new and emerging health technologies & WHO & 2011 \\
$\begin{array}{l}\text { Medical device donations: considerations for solicitation and } \\
\text { provision WHO medical device technical series }\end{array}$ & WHO \\
$\begin{array}{l}\text { Compendium of new and emerging health technologies } \\
\text { Medical device donations: considerations for solicitation and }\end{array}$ & WHO WHO \\
provision WHO medical device technical series & \\
$\begin{array}{l}\text { Medical devices: managing the mismatch } \\
\text { Barriers to innovation in the field of medical devices }\end{array}$ & WHO \\
$\begin{array}{l}\text { The World Bank. HNP Brief \#8: an overview of medical device } \\
\text { policy and regulation. Washington DC: The World Bank }\end{array}$ & WHO World Bank \\
$\begin{array}{l}\text { Medical device regulations global overview and guiding principles } \\
\text { Guidelines for healthcare equipment donations }\end{array}$ & WHO \\
$\begin{array}{l}\text { NGOs } \\
\begin{array}{l}\text { PQMD guidelines for quality of medical product donations } \\
\text { SOS donation guidelines }\end{array}\end{array}$ & WHO Partnership for Quality Medical Donation \\
$\begin{array}{l}\text { Guidelines for donating medical equipment and supplies to low- } \\
\text { income countries }\end{array}$ & Supplies Overseas \\
$\begin{array}{l}\text { CHA medical surplus donation study: how effective donation can } \\
\text { relieve human suffering }\end{array}$ & Catholic Health Association \\
\hline
\end{tabular}


Table 1 Continued

\begin{tabular}{|c|c|c|}
\hline & Author & Year \\
\hline $\begin{array}{l}\text { Making it work: a toolkit for medical equipment donations to low- } \\
\text { resource settings }\end{array}$ & Tropical Health Education Trust & 2008 \\
\hline Used equipment donations programme & $\begin{array}{l}\text { International Organisation for Medical } \\
\text { Physics }\end{array}$ & 2006 \\
\hline SSCSIP Biomedical Meeting for PICs generic donation policy & SSCSIP & - \\
\hline Guidelines on medical equipment donation & $\begin{array}{l}\text { The Pharmaceutical Programme-WCC } \\
\text { and CISS }\end{array}$ & - \\
\hline $\begin{array}{l}\text { The eye care equipment minute-best practices for medical } \\
\text { equipment donations }\end{array}$ & Cybersight & - \\
\hline Guidelines on medical equipment donation & $\begin{array}{l}\text { A Publication of the Pharmaceutical } \\
\text { Programme-WCC and CISS }\end{array}$ & - \\
\hline General donation and medical equipment guidelines & Evangelism Through Medicine & - \\
\hline
\end{tabular}

CISS, Community Initiatives Support Services; NGO, non-governmental organisation; WCC, World Council of Churches.

exist. ${ }^{29-35}$ National documents provide more concrete rules and regulations for equipment donation and may request integration into existing plans for public health improvements. ${ }^{15} 36$ Afghanistan, Ethiopia, Jamaica and Palestine have government committees who oversee all donations and specify functional requirements for donated equipment. $^{30}$ 32-34 37 The Medical Council of India takes control of where donations are sent on a needs basis but assists by waving customs duty and organising transportation. ${ }^{37}$

Aside from national policy documents, there are multiple ways to ascertain the most suitable equipment for donation. Adherence to the WHO principles of good donation is recommended, ensuring maximum benefit for the recipient and respecting their wishes and context (see box 1). Guidelines encourage recipient hospitals to create lists of their prioritised equipment needs, including model specifications, spare parts and

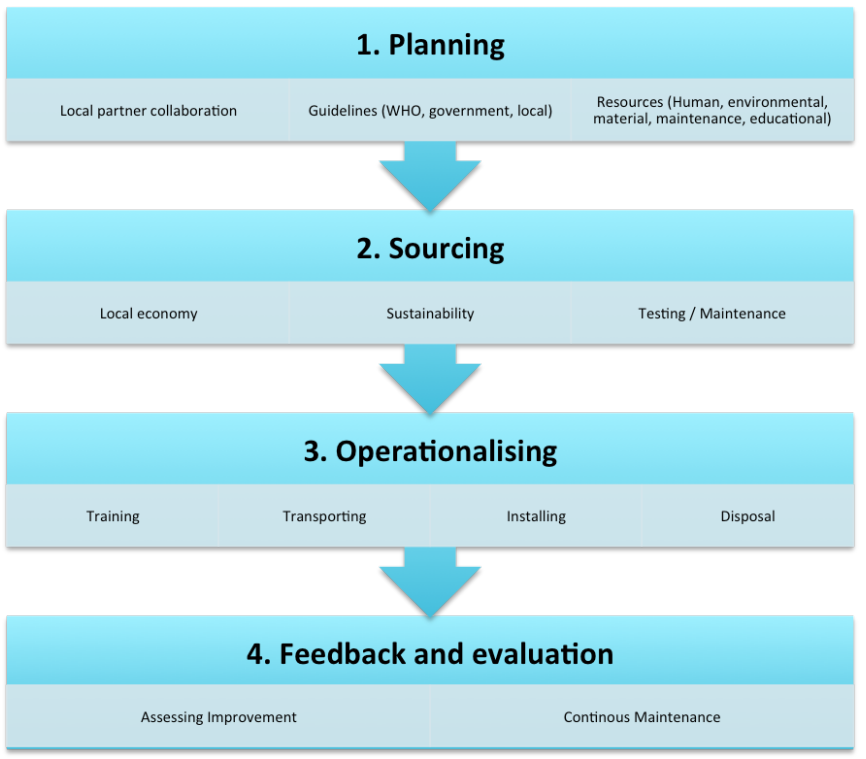

Figure 1 Demonstrates visually the steps required in planning a medical equipment donation project. training requirements. ${ }^{82}$ In the absence of locally identified equipment priorities, a needs assessment should be undertaken. ${ }^{1}$

Review of the published literature revealed many examples of failed donation planning. A study of 43 LMICs showed that up to a third of all donations occurred with no prior consultation. ${ }^{38}$ Low-priority yet expensive equipment, such as ultrasound machines or laparoscopic surgical equipment, has been donated without adequate assessment of local needs, availability of professional services or consumable supplies. The Catholic Health Association found that $60 \%$ of donors were providing broken equipment, the sorting and disposal of which consumed valuable staff time at recipient hospitals. ${ }^{15}$

Adequate communication between recipients and donors during the planning stages was commonly discussed as an important attribute for donation success. ${ }^{27} 28$ Fostering long-term partnerships improves sustainability, builds capacity, and guarantees stable and reliable supply chains. ${ }^{27}$ Unsuitable donations can be costly to both sides; therefore, recipients must be free to turn down inappropriate equipment and discuss donor mistakes. ${ }^{39}$ Reports from LMICs suggest that 'short-term interest' of donors can adversely affect donations and that short-term healthcare trips without follow-up can mean that errors are not identified or fed back. ${ }^{40}$

\section{Standardisation}

Many guidelines require donated equipment to meet international safety standards. ${ }^{9} 29343541$ However, current international standards' reliance on stable power supplies and large maintenance workforces has led some

\section{Box 1 WHO's ${ }^{25}$ four principles of good donation}

Ensure maximum benefit to the recipient.

- Respect the wishes and context of the recipient.

The avoidance of quality double standards.

- Effective donor-recipient communication and planning. 


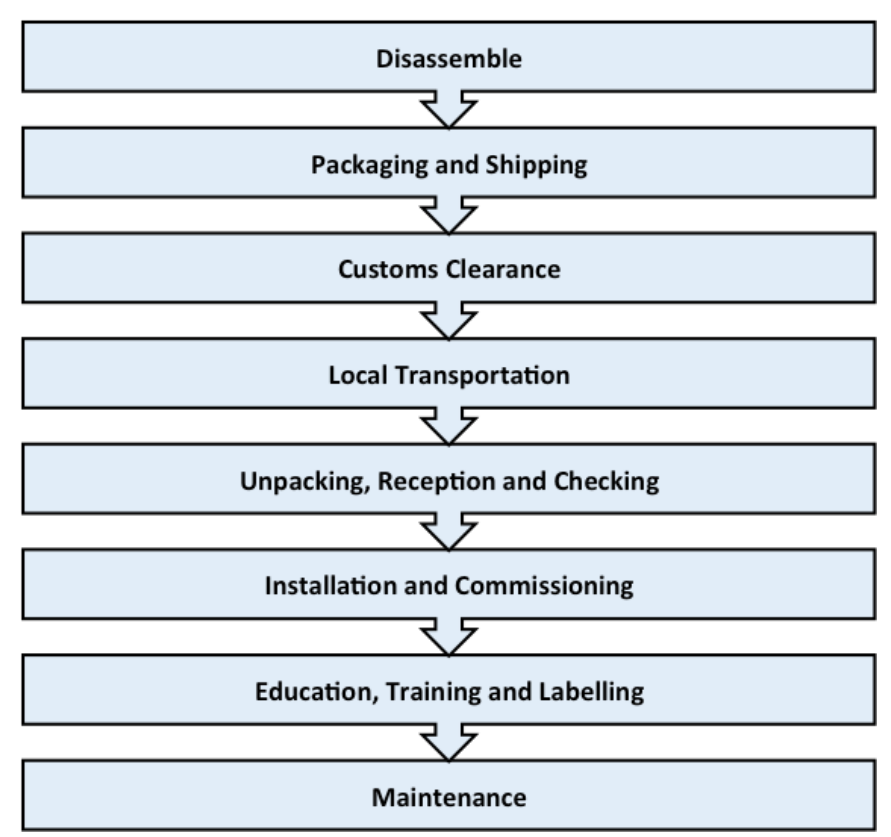

Figure 2 Transportation of donated equipment.

to advocate for situation-specific standards. The World Federation of Societies of Anaesthesiologists has created specific low-resource standards (see online supplementary material).

\section{Sourcing}

Safe and sustainable equipment sourcing for donation can be complex and must be treated with the same rigour as any other type of equipment procurement. ${ }^{12} 28$ Some literature suggested that purchasing new equipment can be more cost effective than recycling used items, given the possibility of payment plans, guaranteed spare parts and up-to-date training. ${ }^{40}$ Given that purchase cost is a small proportion of the complete operating cost, one must also consider the cost of freight, installation, training, operation and maintenance. ${ }^{9} 2736$

The multiplicity of sourcing is problematic for recipient countries. One Asian hospital used autoclaves from four different companies, all requiring different spare parts. ${ }^{40}$ Such a patchwork of providers and motivations poses significant difficulties in LMICs with a lack of standardisation affecting both maintenance and supply chains. Local purchasing avoids delays and problems with servicing associated with centrally purchased and distributed equipment, as well as improving after-sales support. ${ }^{26} 40$

Consideration of cost to both the donor and the local economy is necessary. Expensive used or refurbished items, such as CT scanners or laboratory equipment, offer an opportunity for real savings but are high-risk donations, given their complex infrastructure requirements at the recipient hospital. ${ }^{36}$ Unsophisticated equipment, such as hospital beds or operating tables, may be appropriate for donation, provided they are obsolete rather than worn out. ${ }^{25}$ However, the cost of shipment must be weighed against the cost of locally produced alternatives to mitigate the risk of undermining local businesses. India has tackled this by stipulating in their guidelines that they will refuse any donations of equipment already made in India. ${ }^{37}$

Medical equipment donation groups exist for both profit and not-for-profit. Equipment can be purchased directly from manufacturers, from secondhand retailers and refurbishers, or from NGOs, either locally in the recipient country, the donor country or elsewhere. Medical surplus recovery organisations are a new and largely unregulated industry, but can lack necessary rigour in assessing used equipment. ${ }^{15}$ If used, equipment must be sterile and must include instructions on the method of resterilisation. ${ }^{341}$

It is recommended that donated equipment be fully operational, arriving with essential supplies and accessories. Some governments, such as the Ministry of Health of Ethiopia, require a donor organisation donating non-functioning equipment to pay for disposal. ${ }^{34}$ Equipment that requires spare parts are more beneficial when such parts can be sourced locally, preventing delays in restocking. Operations and service manuals are necessary in assessing the usability of the donated equipment and in providing a checklist for supplies. ${ }^{25}$ Such documents are cited in almost every guideline reviewed but have been found in less than half of surveyed donations in LMICs. ${ }^{18}$

\section{Consumables}

Donating single-use items to settings where reuse is inevitable is problematic, and there is little evidence of long-term benefit. ${ }^{12}$ Guidelines vary in the expiration date standards; some require donations to be in date at the time of donation, ${ }^{41}$ while others require items to be donated at least 12 months ${ }^{35}$ to 2 years before expiration. ${ }^{42}$ The risk of reuse must be considered: needles must never be reused, whereas reusing sterilised tracheal tubes and face masks may be acceptable. ${ }^{43}$ Expired equipment may also be suitable for teaching purposes. ${ }^{44}$ Decontamination may be required to remove pre-existing patient material, and some governments require certification of this. ${ }^{34}$ There was also no mention of the environmental impact of the donation of consumables within our literature search; however, this is emerging within the procurement literature. ${ }^{45} 46$

\section{Transportation and installation}

Transporting medical equipment can be an arduous process and may involve many stages, as demonstrated in figure 2. Before dispatching equipment, the WHO recommends performing an operational verification procedure to ensure it is safe and performs within the manufacturer's specifications. ${ }^{25}$ There is sparse evidence on adequate equipment testing and few guidelines allude to it. A study of donor hospitals in Saudi Arabia found that, while over $80 \%$ of hospitals will run electrical checks, only a third will check mechanical integrity or radiation safety. ${ }^{31}$ Copies of operational and service manuals, in the 


User Training
- How to use equipment safely and
properly
- How to understand the user
manual
- What to do if a problem is
suspected
- How to care for the equipment
- How to interpret results to alter
clinical management

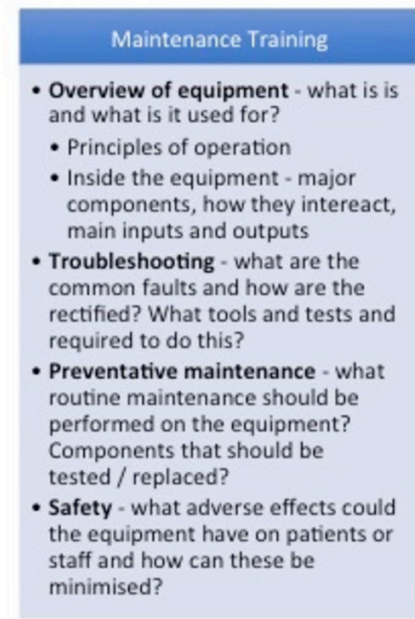

Figure 3 User training (adapted from Tropical Health and Education Trust Toolkit on medical equipment donation).

appropriate language, should be sent separately from the shipment, and additional copies kept with the donors. ${ }^{25}$ Adequate packaging and waterproofing is necessary for fragile equipment. ${ }^{25}$

Correlation of equipment arrival with site preparation, renovation and training is important for donation success. ${ }^{47}$ Guidelines suggest that a time lag between equipment delivery and installation can lead to equipment remaining uninstalled indefinitely, or else installation long after concomitant training has taken place. ${ }^{27}$ Disposal of old equipment can also involve lengthy and complicated procedures, which can create a backlog of discarded equipment that may affect the donation process. ${ }^{40}$

Up to $25 \%$ of equipment reported to be out of service could potentially work if installed properly. ${ }^{25}$ On arrival, donation recipients (preferably skilled technicians) should check for damage or missing parts. Vigilance is necessary at this point to ensure donated equipment is not diverted for export or commercial sale or into 'illicit channels'. Consideration of location, safety requirements, accessibility, floor-loading capacity, electrical power, water volume, pressure and drainage is recommended. ${ }^{18} 36$

Adapting equipment to low-resource settings can prove problematic. Issues include adapting for lack of fixed voltages or compressed gas supplies in recipient countries. ${ }^{14}$ Particular care also needs to be taken to identify any extremes of temperature, humidity, dust and electrical power fluctuations that could adversely affect the equipment's operation or render it inoperable. ${ }^{48}$ Voltage stabilisers may also be necessary to protect equipment against power surges, which can be common occurrences in LMICs. ${ }^{40}$

Accessibility and clear understanding of warranties and documentation is necessary to ensure that repair work will be sought and undertaken immediately. ${ }^{25}$ Some recommend that key information such as name, address and telephone numbers of the company responsible for service or warranty should be placed next to the equipment.

\section{Training}

Training can be performed by recipients, donors, supplier representatives or biomedical engineers. Training is necessary to avoid compromises in patient safety and equipment breakdown. ${ }^{27}$ Essential teaching topics for users are outlined in figure 3. Key topics include proper use and safety, interpretation of results, troubleshooting and preventative maintenance. ${ }^{27}$ Clinicians and maintenance staff training together helps rapport development and aids future communications should equipment malfunction. ${ }^{27}$

Less than half of the donation programme from the 'Partnership for Quality Medical Donations' conducted training as part of their donation programme. ${ }^{49}$ Training of maintenance staff is particularly neglected by donors, with $60.0 \%-82.5 \%$ of biomedical engineers receiving no maintenance training for donated equipment. ${ }^{27} 3638$ Estimates suggest a $30 \%-80 \%$ reduction in useful life of equipment due to inexperienced operators and lack of repair. ${ }^{1}$

\section{Maintenance}

Once in service, regular inspection, maintenance and calibration are widely recommended in the guidelines reviewed. Inventory management techniques are useful for keeping track of spare parts and ensuring that critical components are always in stock. ${ }^{36}$ Documentation, including names of manufacturers or refurbishers, and details of the previously repaired parts should be provided to the recipient hospital, along with any manufacturer guarantees. ${ }^{25}$

It has been recommended that posters in local languages should be placed on the wall close to the equipment with key steps in equipment use, as well as instructions on cleaning and storage. ${ }^{27}{ }^{40}$ Health centres in Tanzania, for example, have kept systematic equipment records on the wall of each ward, to be signed and dated by supervisors, allowing for easy identification of non-functioning or missing equipment. ${ }^{28}$

Biomedical maintenance departments remain one of the most neglected services in many hospitals. A study of 5 sub-Saharan African countries demonstrated that less than half of hospitals assessed had equipment repair and maintenance services. ${ }^{50} \mathrm{~A}$ World Bank report of an Indian state described that $2 \%-5 \%$ of a district hospital's budget was allocated to 'machinery and equipment', but only $0.02 \%-0.06 \%$ was allocated to maintenance, highlighting the limited investment in equipment repair. ${ }^{51}$

Availability of human resources qualified to conduct maintenance, such as biomedical engineers or technicians, is a considerable problem. Approximately $60 \%$ of LMICs demonstrated maintenance departments that were understaffed, and studies found that $80 \%$ of hospitals in the African region struggled to find appropriately experienced engineers. ${ }^{152}$ This problem is even 
more pronounced on the subspecialty level, where items described as 'high maintenance', such as high-speed drills used in neurosurgery, were found to be broken and out of use after donation in a global review. ${ }^{53}$

\section{Follow-up and evaluation}

Follow-up of donation aids the long-term sustainability of equipment and helps to avoid repetition of mistakes. A continued and lasting partnership between the donor and recipient organisations can help sourcing spare parts and support the evaluation process. ${ }^{25} 54$ Evaluation must take place bilaterally. ${ }^{86} 35$ Both donors and recipients must not hesitate to identify mistakes made by either side. ${ }^{29} \mathrm{~A}$ thorough evaluation of the donation can be done via questionnaire, such as those provided by Tropical Health and Education Trust (THET) ${ }^{27}$ Periodic evaluation is important for assessing impact, as well as recording success. ${ }^{40} 41$

\section{DISCUSSION}

This novel literature review investigating the donation of medical equipment for surgical and anaesthesia care in LMICs has demonstrated a high level of complexity within the donation process and numerous shortcomings in existing practice. While it is difficult to know the true scale of medical donation globally, existing peer-reviewed and grey literature suggests that few take into account existing guidelines when designing equipment donation schemes. It is clear, however, that good intentions are not enough to ensure useful, relevant and sustainable donation.

Well-planned and executed donation is frequently cited as a necessary part of the solution to inadequate medical equipment in low-resource settings. A concerted advocacy effort is required to encourage ethical donation and procurement by donors. While redressing the power imbalance between donors and recipients is a complex task, education on both sides can improve the donation process. Donors must listen to and work with recipients, and recipients must find their voice, whether through policy or partnership, in order to reject unhelpful and costly donations. Encouragement of national and local policy creation and equipment prioritisation lists may help this process and empower recipients to discourage unsuitable donations. ${ }^{55}$

Lack of adherence to or knowledge of existing guidelines is a significant barrier to good donation. WHO guidelines on equipment donation were designed to be incorporated into institutional or national guidelines, but there is little evidence that this has been achieved. Where national guidelines exist, it is important that they are respected by international donors. Further research is required to monitor whether groups are opting to follow this protocol, while advocating for governments to do so may be a valuable contribution to improving equipment provision.
Sharing stories, even informally via blogs, videos or websites, can help develop relationships and promote donation education. Publications related to equipment donation remain scarce, as do reports on the efficacy of WHO guidelines. A push towards publication of the impact of donation may help to raise awareness of the pitfalls of donation projects, increase adherence to WHO guidelines and further the creation of evidence-based national and hospital policies.

Significant work is required to redress the imbalance of investment between the frontline health workforce and maintenance departments in LMICs. Biomedical engineer training has been slow to develop to help address this. However, some programmes have begun to recognise the complex nature of biomedical equipment and associated health technology management, such as THET's medical equipment partnerships in five African countries. ${ }^{56}$

While such a structural shift may take many years of investment, donors must carefully consider maintenance budgets when assessing the feasibility and impact of their suggested donations, particularly regarding the ongoing cost burden of related consumables. Furthermore, cultural practices in the hospital environment can significantly affect maintenance of equipment. Under-reporting breakdown is common, and the "use it until it breaks and then request a new one' attitude is widespread. ${ }^{12}$ Engaging donors, recipients, users and support staff may help to guide practice and improve equipment lifetime.

The environmental implications of donated equipment must also be considered. Unintended consequences of donation for humanitarian purposes can be devastating, such as the use of mosquito nets for fishing, to the extreme detriment of marine wildlife. ${ }^{57}$ This is particularly poignant, given the rise in single-use medical equipment worldwide.

The sourcing of equipment remains problematic and requires further study. Medical equipment is largely produced in HICs, even those specifically designed for low-resource settings. ${ }^{40}$ Supporting local procurement can encourage emerging markets in the long term and makes spare parts and services cheaper and easier to access. ${ }^{29}$ Further exploration by potential donors of supporting local innovation and technology companies could flourish within partnerships and allow for multidirectional innovation and learning. HICs could also improve their own equipment management through 'frugal innovation', adopting cheaper solutions developed in LMICs. ${ }^{58}$

There are already a number of examples of successful low-cost, locally produced innovations. The Jaipur foot, a prosthetic designed in India in 1968, is now used in 22 countries in Asia, Africa and South America. Locally sourced and quick to assemble, the device is unpatented and costs around $\$ 40$ (2009) compared with the $\$ 8000$ $\$ 12000$ required for a bespoke prosthesis. ${ }^{16}$ Affordable, effective and local health technology solutions also 
include the bicycle centrifuge invented in Nigeria and the Odon device from Argentina. ${ }^{59} 60$ The use of mosquito nets for hernia repair mesh has also been widely used. ${ }^{61}$

There is wide disparity in the availability of medical equipment and health technologies in proportion to global need. Where medical equipment donation is used to address this, the process should be collaborative, effectively planned and in accordance with recipient country or hospital policy. Reviewing the literature identified five key areas that should be considered when assessing the feasibility of equipment donation:

1. Human resources: on-site capacity in terms of trained physicians, nurses and biomedical technicians to operate and maintain the equipment.

2. Environment: space, electricity, water, oxygen supply and ventilation. Standardisation with local equipment, low energy consumption, ease of maintenance and avoidance of environmentally hazardous substances.

3. Material Resources - ancillary equipment supplied either locally or from overseas, as well as replacement parts and associated supply chains.

4. Maintenance resources: workforce training, considering both material and financial capacity.

5. Educational resources: capacity to train the workforce in the clinical implementation of the equipment, as well as in correct interpretation of results.

This pragmatic literature review has a number of limitations. The diversity of the grey literature and published guidelines in this area outside of the catalogued medical literature means some relevant documents may not have been identified by the search methodology used. In addition, most evidence and evaluation of biomedical equipment donation relate to individual programmes and instances. The site-specific nature of these makes broader generalisation of the findings difficult. Nonetheless, this is the first published literature review of this topic and an important baseline for future studies to use in expanding the academic focus on this largely neglected topic.

\section{CONCLUSION}

Medical equipment donation to LMICs is frequently encountered, with well-intentioned donors seeking to improve the capacity for providing safe surgery and anaesthesia in these settings. Yet, poorly planned and executed biomedical equipment donations will not deliver the desired outcomes and may instead unnecessarily burden healthcare providers and organisations in already challenged environments. While there is a shortage of published literature addressing this topic, most guidelines reviewed recommend approaching donation as a collaborative process, with an equitable partnership between donors and recipients. Planning, sourcing, transporting, installing, training, maintaining and evaluating are key topics of discussion within the literature. Funding for maintenance teams and biomedical engineers is a particularly neglected area and should be considered during donation planning. There is also little evidence that published guidelines are currently being adhered to. We recommend a concerted advocacy effort to educate both donors and recipients on the existing equipment donation guidelines and policies. Increased recipient leadership can foster a needs-led, instead of a supply-led, medical equipment donation partnership. Further evaluation of medical equipment donation programmes is required to determine cost-effective and safe solutions to health equipment disparities worldwide.

Acknowledgements With thank Sarah Kessler and Kristine Stave of the Lifebox Foundation for reviewing the draft manuscript, and Godfrey Sama and colleagues of the International Federation of Medical Students' Associations Global Surgery Working Group, now International Student Surgical Network, for their enthusiasm and drive for a better surgical future.

Contributors IHM and EF conceived the project. IHM and HT reviewed the literature. All authors were involved in the drafting and redrafting of the paper.

Funding The authors have not declared a specific grant for this research from any funding agency in the public, commercial or not-for-profit sectors.

Competing interests None declared.

Patient consent for publication Not required.

Provenance and peer review Not commissioned; externally peer reviewed.

Data availability statement All data relevant to the study are included in the article or uploaded as supplementary information.

Open access This is an open access article distributed in accordance with the Creative Commons Attribution Non Commercial (CC BY-NC 4.0) license, which permits others to distribute, remix, adapt, build upon this work non-commercially, and license their derivative works on different terms, provided the original work is properly cited, appropriate credit is given, any changes made indicated, and the use is non-commercial. See: http://creativecommons.org/licenses/by-nc/4.0/.

ORCID iD

Isobel H Marks http://orcid.org/0000-0002-3544-4512

\section{REFERENCES}

1 Meara JG, Leather AJM, Hagander L, et al. Global surgery 2030: evidence and solutions for achieving health, welfare, and economic development. The Lancet 2015;386:569-624.

2 Alkire BC, Raykar NP, Shrime MG, et al. Global access to surgical care: a modelling study. Lancet Glob Health 2015;3:e316-23.

3 GlobalSurg Collaborative. Mortality of emergency abdominal surgery in high-, middle- and low-income countries. Br J Surg 2016;103:971-88.

4 Ng-Kamstra JS, Greenberg SLM, Abdullah F, et al. Global surgery 2030: a roadmap for high income country actors. BMJ Glob Health 2016;1:e000011.

5 Finch LC, Kim RY, Ttendo S, et al. Evaluation of a large-scale donation of Lifebox pulse oximeters to non-physician anaesthetists in Uganda. Anaesthesia 2014;69:445-51.

6 Penoyar $\mathrm{T}$, Cohen $\mathrm{H}$, Kibatala $\mathrm{P}$, et al. Emergency and surgery services of primary hospitals in the United Republic of Tanzania. BMJ Open 2012;2:e000369.

7 Sodhi J, Talati S, Gupta A, et al. Equipment donation: a perspective from a teaching tertiary care hospital in North India. Indian J Sci Res 2014;8:112-4.

8 (WCC) WCoC, (CISS) CISS. Guidelines on medical equipment donation. Available: https://www.humanitarianresponse.info/system/ files/documents/files/medical_devices_donation_guidelines_ summary.pdf: Humanitarian Response

9 Cybersight. Best practices for medical equipment donations Cybersight. Available: https://cybersight.org/

10 Ozgediz D, Chu K, Ford N, et al. Surgery in global health delivery. Mt Sinai J Med 2011;78:327-41.

11 Dzwonczyk R, Riha C, CJRPdSP R. Medical equipment donations in Haiti: flaws in the donation process. Rev Panam Salud Publica 2012;31:345-8.

12 Howie SRC, Hill SE, Peel D, et al. Beyond good intentions: lessons on equipment donation from an African Hospital. Bull World Health Organ 2008;86:52-6. 
13 Abdallah H. Dumped "donations" now a bruden on Ugandan hosptials. The East African, 2014. Available: http://www. theeastafrican.co.ke/news/Dumped-donations-now-a-burden-onUgandan-hospitals-/2558-2507622-li88giz/index.html

14 Gatrad AR, Gatrad S, Gatrad A. Equipment donation to developing countries. Anaesthesia 2007;62:90-5.

15 Catholic Health Assocation of the United States (CHA). Cha medical surplus donation study: how effective surplus donation can relieve human suffering, 2011. Available: https://www.chausa.org/docs/ default-source/general-files/b5c12ee8b2084119b16cd7bd8675 2e221-pdf.pdf?sfvrsn $=0$

16 Howitt P, Darzi A, Yang G-Z, et al. Technologies for global health. The Lancet 2012;380:507-35.

17 Chawla S, Kurani S, Wren SM, et al. Electricity and generator availability in LMIC hospitals: improving access to safe surgery. $J$ Surg Res 2018;223:136-41.

18 Perry L, Malkin R. Effectiveness of medical equipment donations to improve health systems: how much medical equipment is broken in the developing world? Med Biol Eng Comput 2011;49:719-22.

19 Sani R, Nameoua B, Yahaya A, et al. The impact of Launching surgery at the district level in niger. World J Surg 2009;33:2063-8.

20 Organization WH. Barriers to innovation in the field of medical devices: background paper 6, August 2010. Geneva: World Health Organization, 2010.

21 Dyro JF. Donation of medical device technologies. Clinical Engineering Handbook: Elsevier, 2004: 155-8.

22 Petroze RT, Nzayisenga A, Rusanganwa V, et al. Comprehensive national analysis of emergency and essential surgical capacity in Rwanda. Br J Surg 2012;99:436-43.

23 Elkheir N, Sharma A, Cherian M, et al. A cross-sectional survey of essential surgical capacity in Somalia. BMJ Open 2014:4:e004360.

24 Bewes P. Operating theatre and equipment. BMJ 1984;288:1284-6.

25 Organization WH. Guidelines for health care equipment donations. Geneva: World Health Organization, 2000.

26 Organization WH. Medical device donations: considerations for solicitation and provision. Report no: 92415014052011.

27 Mullally S. Making it work: a toolkit for medical equipment donations to low-resource settings. THET, 2013. Available: https://www.thet. org/wp-content/uploads/2017/08/THET_MakingltWork_Toolkit_ Final_Online.pdf

28 Zomboko FE, Tripathi S. Challenges in procurement and use of donated medical-equipments: study of a selected referral hospital in Tanzania 2012;3:41-8

29 Organization WH. Medical device regulations: global overview and guiding principles 2003.

30 Daniel H. Policy and procedures guidelines for gifts and donations to the Ministry of health Jamaica, 2014. https://www.moh.gov. $\mathrm{jm} / \mathrm{wp}$-content/uploads/2015/03/Ministry-of-Health-Gift-PolicyAuthorization.pdf

31 SFDA. National comprehensive study on the associated risks, donation and disposal of used medical devices in the Kingdom of Saudi Arabia. Available: https://www.sfda.gov.sa/en/medicaldevices/ studies/Documents/NationalComprehensiveStudyonTheAssociate dRisksDonationandDisposalofUsedMedicalDevicesinKSA.pdf

32 Health PNAMo. Guidelines for medical equipment, spare parts, and maintenance services donation. Palestinian national authority Ministry of health, 2014. Available: http://www.lacs.ps/ documentsShow.aspx?ATT ID $=15567$

33 Health TIGoAMo, Department HCaP, Affairs DoP. Guidelines on medical equipment donations. transitional Islamic government of Afghanistan, 2003. Available: http://lyon-kaboul.univ-lyon1.fr/ politique_de_sante_en_afghanistan/rapports/Guidelines\%20on\% 20Medical\%20Equipment\%20Donations.pdf

34 Denekew Y. Medical equipment donation Directive No. 9/2012. Ethiopian food, medicine and healthcare administration and control authority, 2012. Available: http://www.frankshospitalworkshop.com/ organisation/management_documents/Medical\%20Equipment\% 20Donation\%20Directive\%20-\%20Ethiopian\%20Healthcare\% 20Authority.pdf

35 SSCSIP. Generic donation policy. strengthening Speciliased clinical services in the Pacific (SSCSIP), 2013. Available: http://sscsip.org/ wp-content/uploads/2013/07/donation policy1.pdf

36 Malkin RA. Design of health care technologies for the developing world. Annu Rev Biomed Eng 2007;9:567-87.

$37 \mathrm{MCo}$ I. Guidelines for equipment donation scheme. Medical Council of India, 2016. Available: https://mciindia.org/AboutMCl/ CMEProgrammes/GuidelinesforEDSScheme.aspx

38 Mullally S, Frize M. Survey of clinical engineering effectiveness in developing world hospitals: equipment resources, procurement and donations. 2008 30th annual International Conference of the IEEE engineering in medicine and biology Society; 2008 20-25 AUG, 2008.

39 Welling DR, Ryan JM, Burris DG, et al. Seven SINS of humanitarian medicine. World J Surg 2010;34:466-70

40 Mavalankar D, Raman P, Dwivedi H, et al. Managing equipment for emergency obstetric care in rural hospitals. Int J Gynaecol Obstet 2004;87:88-97.

41 PQMD. PQMD guidelines for quality medical product donations. The partnership for quality medical donations (PQMD), 2016. Available: http://www.pqmd.org/wp-content/uploads/2015/07/PQMDStandard-V5-April-2016.pdf

42 SJHS. Guidelines for Donating Medical Equipment and Supplies to Developing Countries. Guidelines for Donating Medical Equipment and Supplies to Developing Countries St. Joseph's Health System: St. Joseph's Health System International Outreach Program 2015.

43 Bösenberg AT. Pediatric Anesthesia in Developing Countries. In: Coté CJ, Lerman J, Anderson BJ, eds. A practice of anesthesia for infants and children (sixth edition. Philadelphia2, 2019: 1161-74.

44 Lazzara EH, Benishek LE, Dietz AS, et al. Eight critical factors in creating and implementing a successful simulation program. Jt Comm J Qual Patient Saf 2014;40:21-9.

45 McGain F, Story D, Lim T, et al. Financial and environmental costs of reusable and single-use anaesthetic equipment. Br J Anaesth 2017;118:862-9.

46 Unger S, Landis A. Assessing the environmental, human health, and economic impacts of reprocessed medical devices in a Phoenix hospital's supply chain. J Clean Prod 2016;112:1995-2003.

47 Theodorou M, Georgiou M, Nikolentzos A, et al. Reconsidering planning and management of medical devices procurement in public health services in Cyprus. Glob J Health Sci 2015;7:205-14.

48 Rosen MA, Lee BH, Sampson JB, et al. Failure mode and effects analysis applied to the maintenance and repair of anesthetic equipment in an austere medical environment. Int J Qual Health Care 2014:26:404-10.

49 Jenny AM, Li M, Ashbourne E, et al. Assessment of the scope and practice of evaluation among medical donation programs. Global Health 2016;12.

50 Hsia RY, Mbembati NA, Macfarlane S, et al. Access to emergency and surgical care in sub-Saharan Africa: the infrastructure gap. Health Policy Plan 2012;27:234-44.

51 Alderman H, Chiappori P-A, Haddad L, et al. India-New directions in health sector development at the state level: an operational perspective. Report no: 0821300342 contract no: report No. 15753IN, 1997.

52 Glouhova M, Kolitsi Z, Pallikarakis N. International survey on the practice of clinical engineering: mission, structure, personnel, and resources. J Clin Eng 2000;25:269-76.

53 Venturini S, Park KB. Evaluating the effectiveness and the impact of donated neurosurgical equipment on neurosurgical units in low- and middle-income countries: the world Federation of neurosurgical societies experience. World Neurosurg 2018;109:98-109

54 GoSLMoH S. Guidelines for the Donation of Medicines, Medical Supplies and Equipment to Sierra Leone. Government of Sierra Leone Ministry of Health \& Sanitation 2004.

55 Diaconu K, Chen Y-F, Cummins C, et al. Methods for medical device and equipment procurement and prioritization within low- and middle-income countries: findings of a systematic literature review. Global Health 2017;13:59.

56 Worm A, Schofield R. How the THET partnership model is different; looking back at two years of medical equipment partnerships in five African countries: THET, 2019. Available: https://www.thet.org/ resources/1690/

57 Bush ER, Short RE, Milner-Gulland EJ, et al. Mosquito net use in an artisanal East African fishery. Conserv Lett 2017;10:451-9.

58 Crisp N, Capacity GH. Global health capacity and workforce development: turning the world upside down. Infect Dis Clin North Am 2011;25:359-67.

59 WHO. New instrument for assisted vaginal delivery. World health organisation (who), 2018. Available: https://www.who.int/ reproductivehealth/topics/maternal_perinatal/odon_device/en/

60 Soman D, Stein JG, Wong J. Innovating for the global South: towards an inclusive innovation agenda. University of Toronto Press, 2014: 185.

61 Kingsnorth AN, Tongaonkar RR, Awojobi OA. Commentary on: low-cost mesh for inguinal hernia repair in resource-limited settings. Hernia 2011;15:491-4. 